\title{
Hindfoot Arthrodesis with the Blade Plate: Increased Risk of Complications and Nonunion in a Complex Patient Population
}

\author{
Troy M. Gorman MD, Timothy C. Beals MD, Florian Nickisch MD, \\ Charles L. Saltzman MD, Mikayla Lyman BS, Alexej Barg MD
}

Received: 11 January 2016/Accepted: 20 June 2016/Published online: 5 July 2016

(C) The Association of Bone and Joint Surgeons \& 2016

\begin{abstract}
Background Previous hindfoot surgeries present a unique challenge to hindfoot arthrodesis, as the patients may have multiple incisions around the hindfoot. In high-risk patients with compromised soft tissues, a posterior approach can provide an alternative for a fresh soft tissue plane for the surgery. The use of a blade plate construct is widely accepted; however, there are limited data supporting the use of a posterior approach.

Questions/purposes We asked (1) what proportion of patients treated with this technique achieved osseous

Each author certifies that he or she, or a member of his or her immediate family, has no funding or commercial associations (eg, consultancies, stock ownership, equity interest, patent/licensing arrangements, etc) that might pose a conflict of interest in connection with the submitted article.

All ICMJE Conflict of Interest Forms for authors and Clinical Orthopaedics and Related Research ${ }^{\mathbb{R}}$ editors and board members are on file with the publication and can be viewed on request.

Clinical Orthopaedics and Related Research ${ }^{\circledR}$ neither advocates nor endorses the use of any treatment, drug, or device. Readers are encouraged to always seek additional information, including FDAapproval status, of any drug or device prior to clinical use.

Each author certifies that his or her institution approved or waived approval for the human protocol for this investigation and that all investigations were conducted in conformity with ethical principles of research.

This work was performed at the University of Utah, Salt Lake City, UT, USA.
\end{abstract}

\section{T. M. Gorman}

Intermountain Orthopedic Specialty Group, Salt Lake City, UT, USA

T. C. Beals, F. Nickisch, C. L. Saltzman, M. Lyman,

A. Barg $(\square)$

Department of Orthopaedics, University of Utah, 590 Wakara

Way, Salt Lake City, UT 84108, USA

e-mail: Alexej.barg@hsc.utah.edu; alexejbarg@mail.ru union; (2) what complications were observed; (3) were any patient-demographic or health-related factors associated with the likelihood that a patient would have a complication develop?

Methods Between December 2001 and July 2014, 42 patients received a posterior blade plate. During the period in question, indications for hindfoot arthrodesis using posterior blade fixation were subtalar osteoarthritis below an ankle fusion, malunion or nonunion, failed tibiotalocalcaneal arthrodesis attributable to nonunion of the tibiotalar and/or subtalar joint; or tibiotalar and subtalar osteoarthritis in patients with impaired bone or soft tissue quality (particularly if the soft tissue problem was anterior). During that period, all patients who met those indications were treated with a posterior blade plate. Forty (95\%) were included in this study, and two were lost to followup before the 1-year minimum required by the study. Demographics (age, gender, BMI, smoking status, and comorbidities) and surgical data (indication, previous treatment, and additional procedures) were analyzed. Of the 40 patients included, 27 $(68 \%)$ were male and $13(33 \%)$ were female, with a median of two previous hindfoot or ankle surgeries (range, 0-9 surgeries). The mean age of the patients was $56 \pm 13$ years. Followup averaged $47 \pm 28$ months (range, 14-137 months). Twenty-eight of $40(70 \%)$ patients had a tibiotalocalcaneal arthrodesis as a primary $(n=6)$, primary staged $(n=10)$, revision $(n=9)$, or revision staged $(n=3)$ procedure. Eleven of 40 patients $(28 \%)$ underwent ankle arthrodesis (primary $n=7$, revision $n=4$ ). One of the 40 patients $(3 \%)$ underwent tibiotalocalcaneal arthrodesis for a failed total ankle arthroplasty. Weightbearing radiographs were used to assess fusion. Osseous fusion was defined as visible trabecular bridging on the lateral and AP ankle views within 6 postoperative months. Delayed union was defined as osseous fusion occurring between 6 and 12 
months. Nonunion was defined as no visible trabecular bridging at the latest followup (longer than 12 months). Clinic and surgery notes were reviewed for complications. Univariate analysis was performed to compare patient groups: patients with solid union versus nonunion, and patients with versus without complications.

Results Twenty-nine of 40 (73\%) patients had osseous fusion within 6 postoperative months. Four of 40 (10\%) patients had a delayed union between 6 and 12 months, and seven of the $40(18 \%)$ patients had nonunions, which occurred in the ankle $(\mathrm{n}=3)$, subtalar $(\mathrm{n}=3)$, or both $(\mathrm{n}=$ 1) joints. There were 26 complications observed: 18 (69\%) were considered major and eight $(31 \%)$ were minor. With the numbers available, we did not identify any demographic or surgical factors associated with complications, delayed union, or nonunion.

Conclusions The proportion of patients treated with a posterior blade plate hindfoot fusion who had delayed union or nonunion is greater than that reported for patients in other series who underwent primary hindfoot arthrodesis with other approaches, and the proportion of patients who had complications develop is high. Further studies are needed to address alternative approaches to achieve hindfoot fusion in patients with complex hindfoot problems. Level of Evidence Level IV, therapeutic study.

\section{Introduction}

Different surgical techniques, including intramedullary nails, screws, plates and screws, and external fixators, have been used to achieve hindfoot arthrodesis [20-22, 24, 25]. Often patients who undergo hindfoot fusion have had previous surgical procedures including open reduction and internal fixation (of the ankle, talus, and/or calcaneus), previous ankle arthrodesis, or total ankle arthroplasty. Patients may present with multiple incisions around the hindfoot. Additionally, patients with previous subtalar fusion likely have an additional lateral incision in the region of the sinus tarsi. The choice of the appropriate surgical approach for hindfoot arthrodesis in this setting can be difficult. Surgery is increasingly difficult and more demanding when performed on a limb that had previous hindfoot surgery, especially previous fusion surgery $[3,8,11]$ or total ankle arthroplasty $[10,17,18]$. In highrisk patients with tenuous soft tissue envelopes undergoing salvage surgery, a posterior approach can provide a fresh soft tissue plane for surgery and good coverage of hardware [20].

Few studies have evaluated the use of a blade plate from a posterior approach in this patient population $[1,5,9,14-16,19,27,28]$ (Table 1). Most of these studies are characterized by low number of patients and relatively short followup (Table 1). The two largest series included 14 and 20 patients, respectively [5, 28]. In both studies, patients with trauma who had nonreconstructable pilon fractures were included $[5,28]$. This patient population was without severe medical comorbidities and lacked any history of major previous surgery about the hindfoot. We therefore wished to evaluate a relatively large and diverse population of patients who underwent either tibiotalocalcaneal arthrodesis or tibiotalar arthrodesis using a posterior approach with blade-plate fixation. Primary, staged, and revision procedures were included.

Specifically, we asked (1) what proportion of patients treated with this technique achieved osseous union, (2) what complications were observed, and (3) were any patient-demographic or health-related factors associated with the likelihood that a patient would have a complication develop?

\section{Patients and Methods}

The University of Utah institutional review board approved this retrospective study (IRB \#71733), and informed consent was waived. Patients were identified by searching the University of Utah Department of Orthopaedics' medical database for the period from January 1, 2001, to July 31, 2014.

During the period in question, indications for hindfoot arthrodesis using posterior blade fixation were subtalar osteoarthritis below an ankle fusion, malunion, or nonunion, failed tibiotalocalcaneal arthrodesis attributable to nonunion of the tibiotalar and/or subtalar joint; or tibiotalar and subtalar osteoarthritis in patients with impaired bone or soft tissue quality (particularly if the soft tissue problem was anterior). During that period, all patients who met those indications were treated with a posterior blade plate. The database search yielded 42 patients who each underwent hindfoot arthrodesis (either tibiotalar or combined tibiotalar and subtalar) using a posterior blade plate for fixation through a posterior approach. Minimum followup for inclusion was 12 months (mean, 47 months; range, 14137 months). A total of $95 \%$ (40 of 42 patients) were accounted for (Table 2). Two patients were excluded, one owing to an unrelated death during the early postoperative period and short followup ( 8 months) in the other patient. Twenty-seven of the $40(68 \%)$ patients were male and 13 (33\%) were female, with a mean age of $56 \pm 13$ years (range, 24-83 years) (Table 2). Major comorbidities included diabetes mellitus in 11 of $40(28 \%)$ patients, peripheral neuropathy in 12 of $40(30 \%)$, and tobacco use in 11 of $40(28 \%)$. Patients had undergone a median of two previous hindfoot or ankle surgeries (range, 0-9 surgeries). 


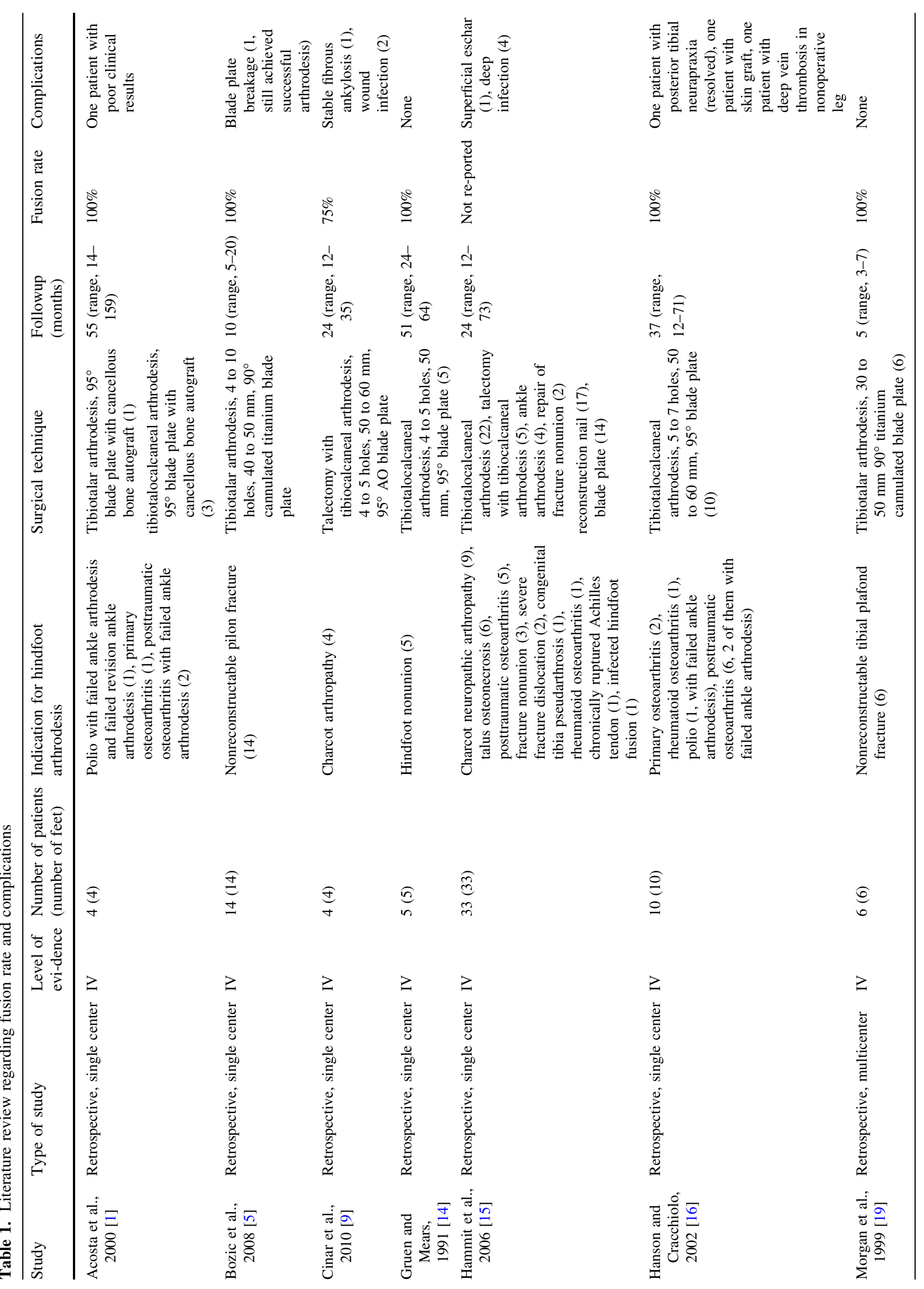




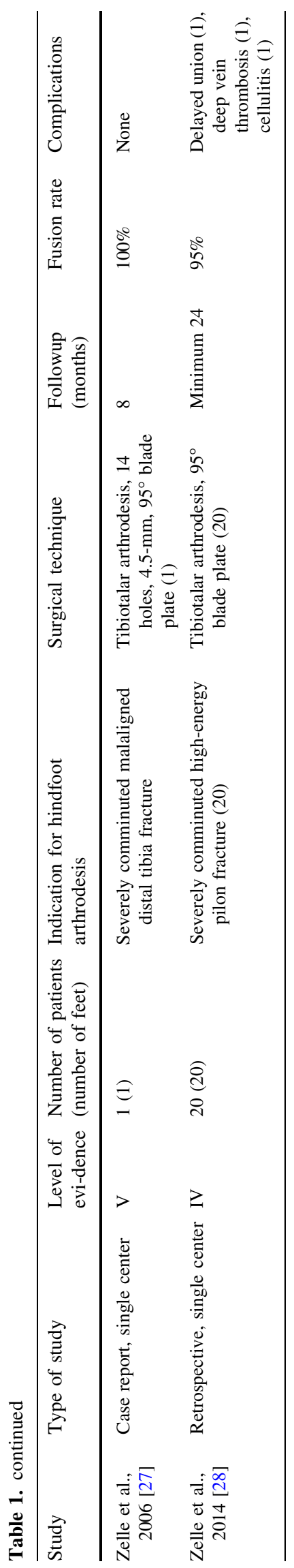

During the study period, numerous other patients underwent hindfoot fusions using other approaches. In general, as noted above, the patients with more-complex disorders were treated using a posterior approach and a blade plate. The patients undergoing tibiotalar and subtalar osteoarthritis who had better bone and soft tissue quality were treated mostly with tibiotalocalcaneal arthrodesis using intramedullary nail fixation. During the study period, in total, 455 hindfoot arthrodeses (isolated tibiotalar arthrodesis or tibiotalocalcaneal arthrodesis) were performed. The approaches for these procedures were as follows: screws $(n=264 ; 58 \%)$, plate $(\mathrm{s})(\mathrm{n}=89 ; 20 \%)$, external fixator $(\mathrm{n}=35 ; 8 \%)$, intramedullary nail $(\mathrm{n}=25$; $6 \%$ ), and the patients in the current series who underwent surgery using a blade plate $(n=42$, or $9 \%$ of the hindfoot fusions performed during the period in question). The patients who underwent fixation using a posterior blade plate were considered not to be good candidates for moretraditional means of fixation owing to loss of bone stock or major soft tissue issues on the anterior aspect of the ankle.

All procedures were performed by three of the authors, all experienced and fellowship-trained orthopaedic foot and ankle surgeons (FN, TCB, CLS). Two authors (TMG, $\mathrm{AB}$ ), who did not operate on any of the patients, independently reviewed chart records and patients' radiographs regarding union rate and possible complications, and performed clinical assessment in the outpatient clinic.

Patients with primary tibiotalocalcaneal arthrodesis underwent primary arthrodesis of the ankle and subtalar joint during the index procedure. Patients with staged tibiotalocalcaneal arthrodesis had successful arthrodesis of the ankle or subtalar joint previously and then had the other joint fused during the index procedure. Patients with revision tibiotalocalcaneal arthrodesis had nonunion of the ankle and subtalar joints after previously attempted tibiotalocalcaneal arthrodesis and underwent revision tibiotalocalcaneal arthrodesis. Finally, patients with revision-staged tibiotalocalcaneal arthrodesis had a previous attempt at a tibiotalocalcaneal arthrodesis in which one of the joints fused but the other progressed to nonunion. Twenty-eight of $40(70 \%)$ patients had a tibiotalocalcaneal arthrodesis in a primary $(\mathrm{n}=6)$, primary-staged $(\mathrm{n}=10)$, revision $(n=9)$, or revision-staged $(n=3)$ setting (Fig. 1). Eleven of $40(28 \%)$ patients had ankle arthrodesis, with seven and four patients having primary and revision ankle arthrodesis, respectively (Fig. 2).

Thirty-eight of 40 (95\%) patients had a popliteal block placed by the anesthesia team preoperatively [2]. An intraoperative "single-shot" antibiotic prophylaxis was performed using intravenous cefazolin unless the patient had an allergy or intraoperative cultures were desired.

After general anesthesia was induced, the patient was placed in the prone position. All surgeries were performed 


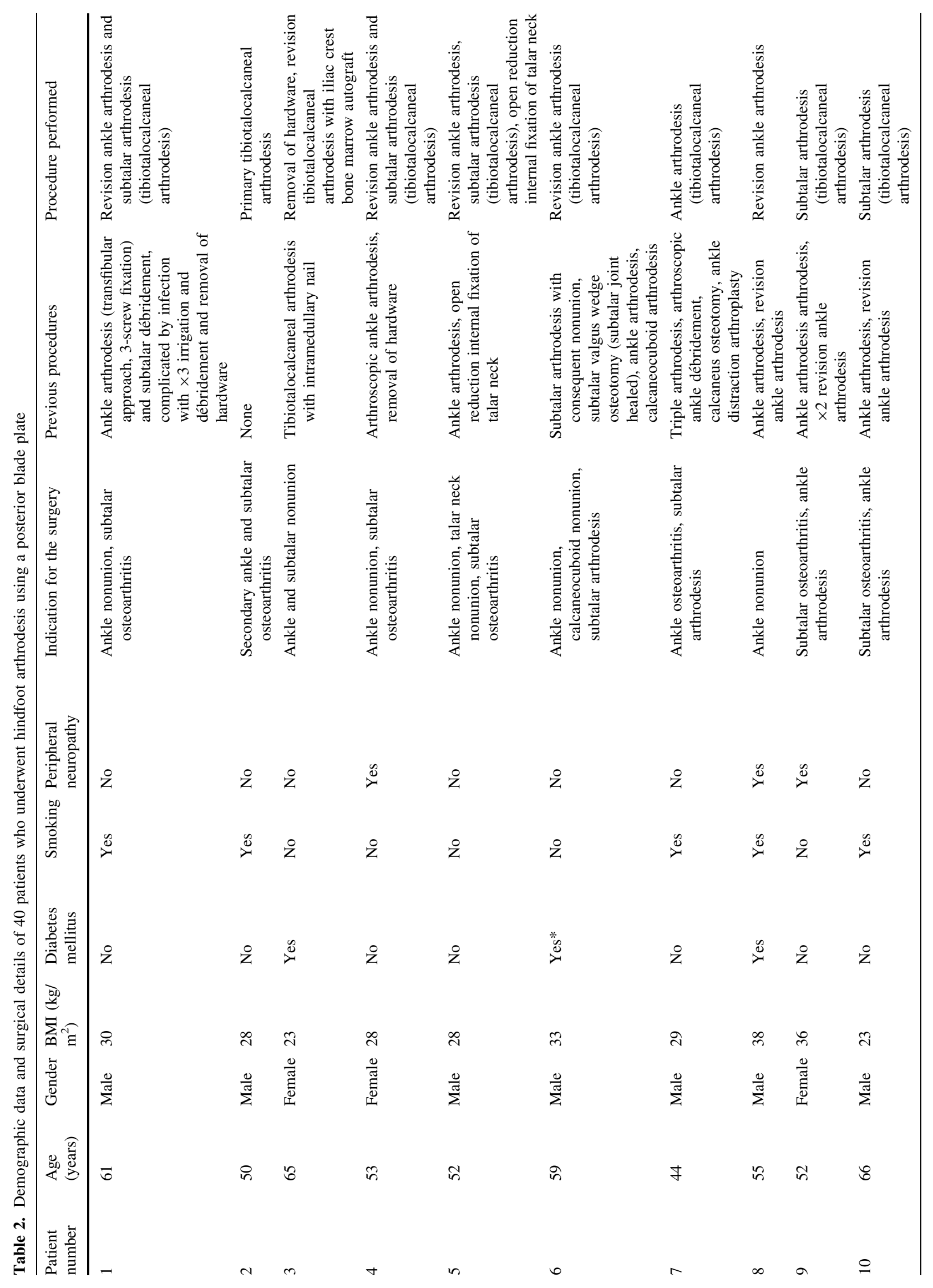




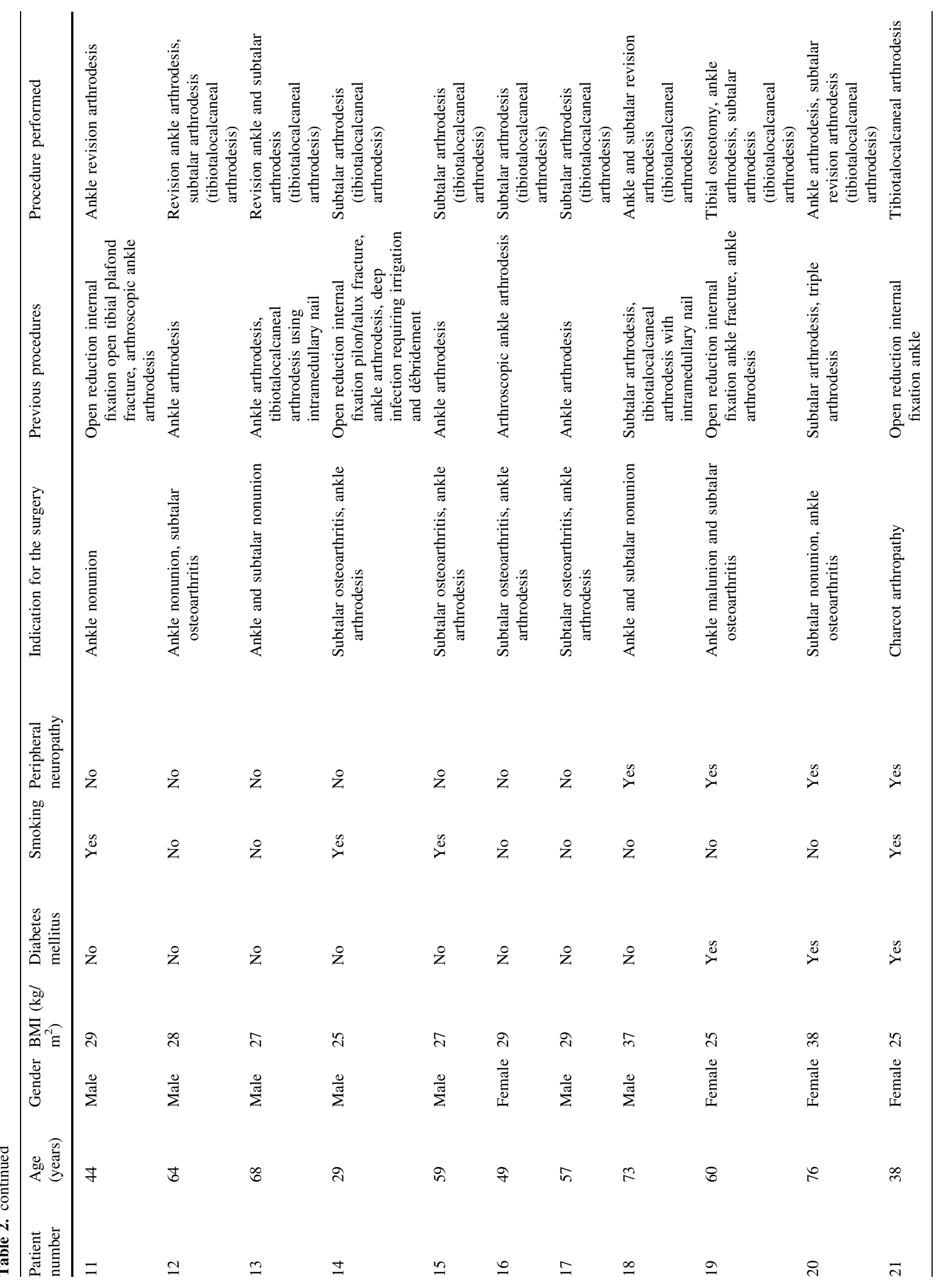




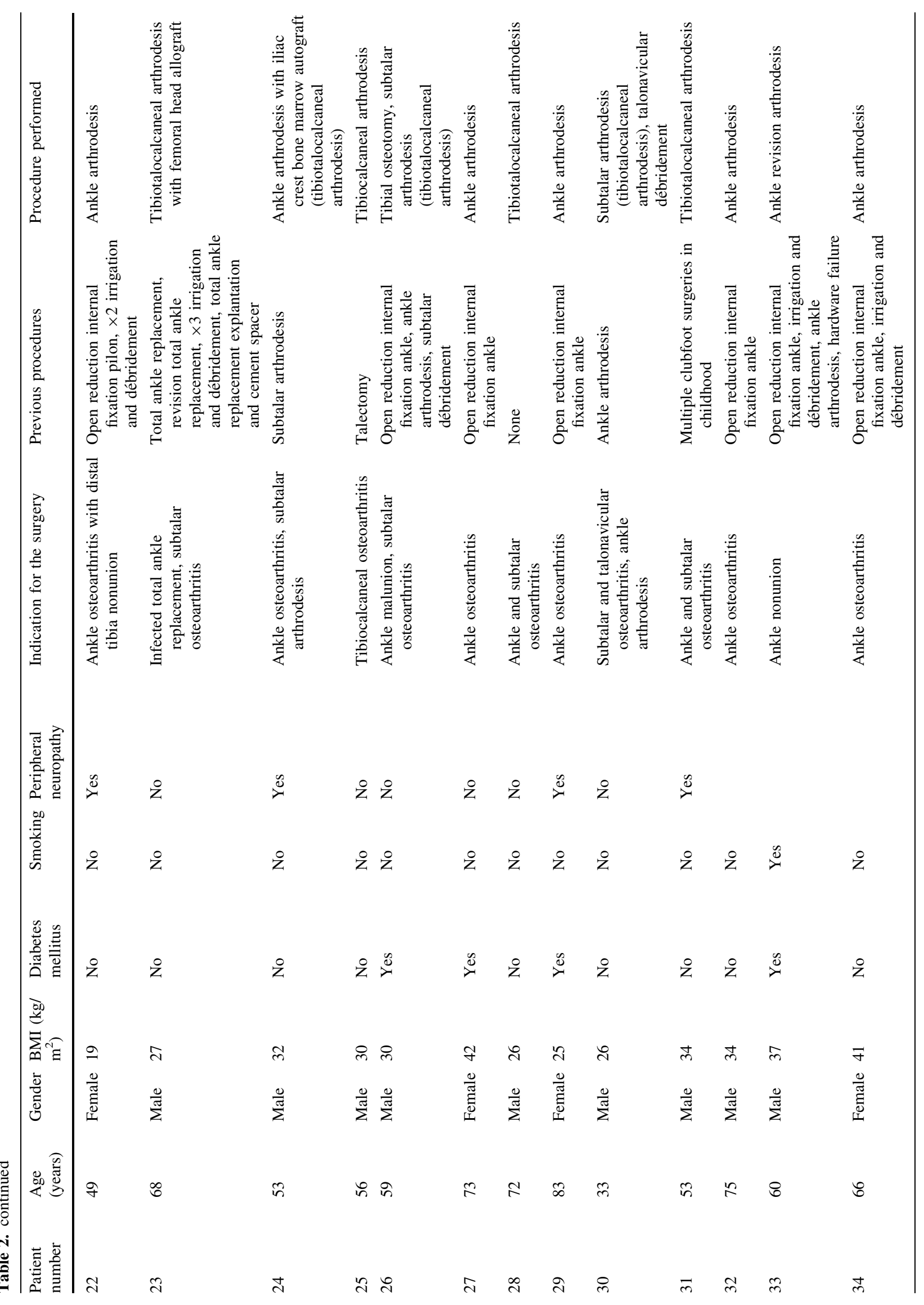




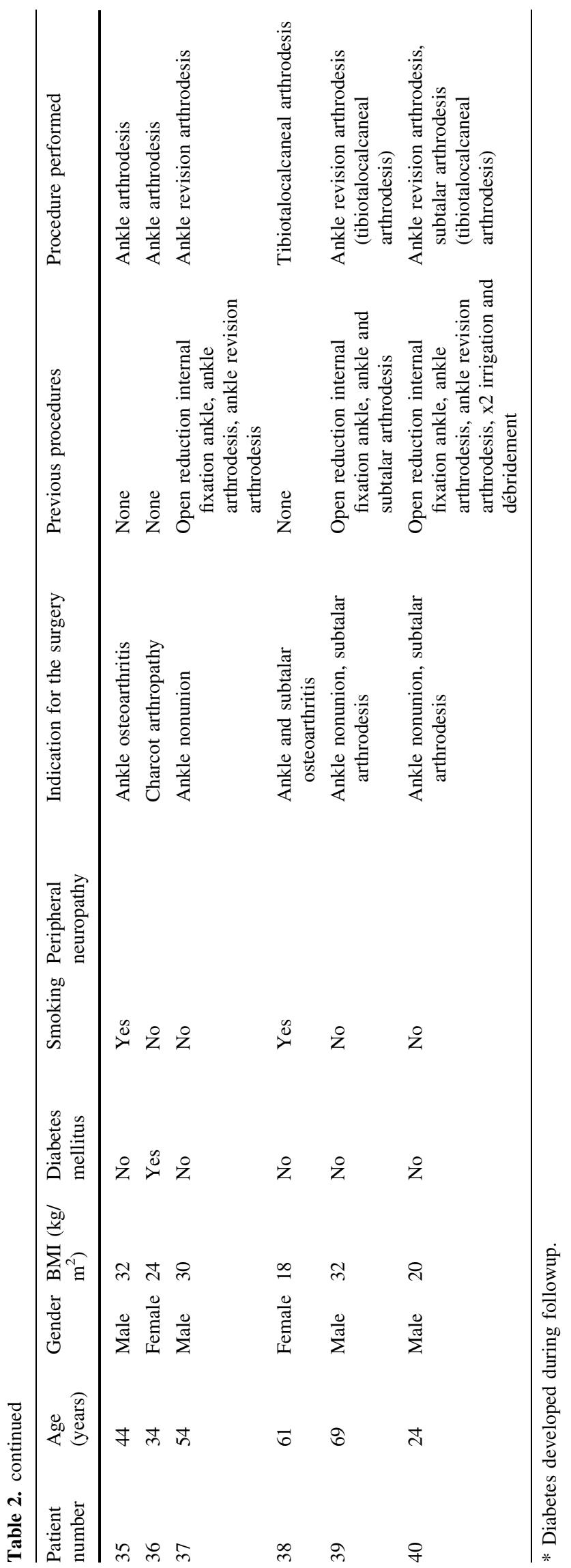

with application of a thigh tourniquet. If previous hardware was going to interfere with posterior blade-plate insertion, the hardware was removed from the most-appropriate previous incision.

A 10- to $12-\mathrm{cm}$ straight, midline, posterior incision was made over the Achilles tendon down to the level of the paratenon (Fig. 3). The paratenon was incised longitudinally and then full-thickness flaps were retracted medially and laterally. A Z-type lengthening of the Achilles tendon then was performed either in the coronal or sagittal plane to achieve neutral alignment of the hindfoot in the sagittal plane. Dissection was carried down to the level of the deep posterior compartment, identifying the fascia over the flexor hallucis longus. The fascia then was opened and the flexor hallucis longus tendon was mobilized medially. By keeping the flexor hallucis longus tendon medially retracted, the neurovascular bundle was protected.

The posterior capsules of the ankle and subtalar joints then were identified and incised. To improve observation of the ankle in procedures involving tibiotalar arthrodesis, the posterior portion of the plafond was removed with an osteotome. The articular surfaces to be fused were then debrided. A 2-mm drill was used to perforate the subchondral bone. An osteotome was used to partially remove the posterior malleolus of the tibia and part of the posterior aspect of the talus to allow the blade plate to fit flush against the posterior tibia. The posterior malleolus was morselized and placed in the arthrodesis site.

An osteotomy of the distal tibia was performed in two ankles with malunion of a previously performed ankle fusion to correct the malalignment (internal rotation and plantar flexion) before additional arthrodesis of the subtalar joint.

After joint surfaces were prepared and bone graft was placed, the hindfoot was reduced to the desired position with the ankle neutral in the sagittal plane, external rotation similar to the healthy contralateral side, and the subtalar joint with approximately $5^{\circ}$ valgus. The alignment was stabilized preliminarily using Steinmann pins, introduced percutaneously from the posteroinferior aspect of the heel. A $3.5-\mathrm{mm}$ cannulated $90^{\circ}$ blade plate (Synthes, West Chester, PA, USA) then was contoured to the posterior aspect of the tibia and slightly bent so the blade would end up just inferior to the sustentaculum tali for cases including the subtalar joint. The guidewire for the blade plate was placed in the calcaneus, and its position was checked on AP, lateral, and axial fluoroscopic images. When the desired position was confirmed, the guidewire was measured to determine the length of the blade. Most often a six-hole, 50-mm blade plate was used (Table 3). Once the proximal portion of the plate was flush against the tibia, a $3.5-\mathrm{mm}$ cortical screw was placed in the calcaneus-from the medial tibial to the 

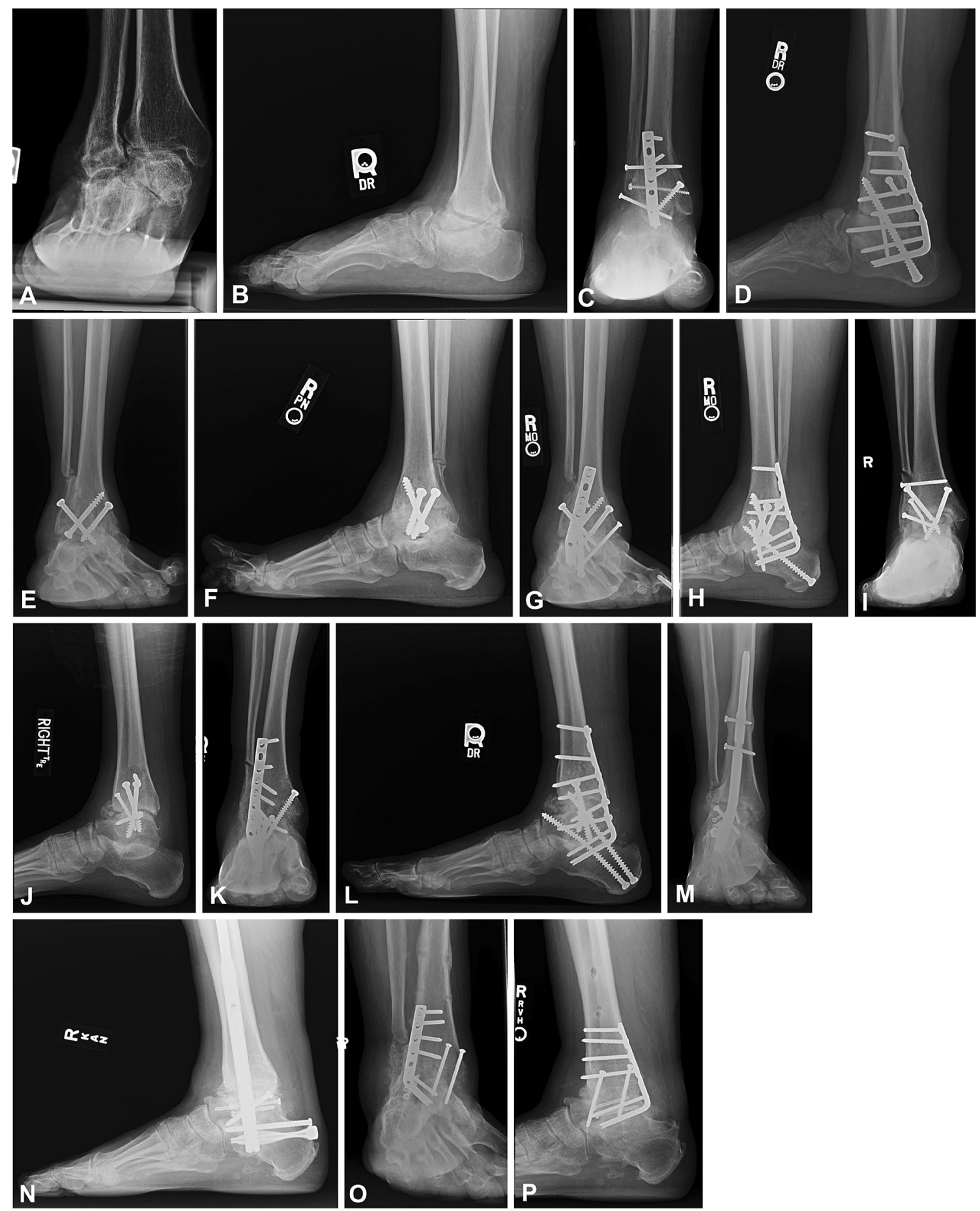

Fig. 1A-P A 53-year-old man had (A) ankle and subtalar osteoarthritis and a complex valgus hindfoot deformity as evident on the AP and (B) lateral radiographic views. (C) AP and (D) lateral radiographs were obtained after the patient underwent primary tibiotalocalcaneal arthrodesis using a posterior blade plate. (E) Subtalar osteoarthritis after a revision tibiotalar arthrodesis in a 52year-old female patient is seen on the AP and (F) lateral radiographic views. (G) A mortise view of the patient's ankle was obtained after a primary-staged tibiotalocalcaneal arthrodesis. (H) A lateral view shows the tibiotalocalcaneal arthrodesis with a posterior blade plate. For a 64-year-old male patient, the (I) AP and (J) lateral view

radiographs show a tibiotalar nonunion and subtalar osteoarthritis $(\mathbf{K})$ A postoperative radiograph obtained after a revision tibiotalocalcaneal arthrodesis is shown. (L) The lateral view radiograph shows the revision tibiotalocalcaneal arthrodesis with a posterior blade plate. A 67-year-old male patient experienced (M) tibiotalar nonunion after an attempted tibiotalocalcaneal arthrodesis using intramedullary fixation as seen on the AP and (N) lateral view radiographs. The patient underwent a revision-staged tibiotalocalcaneal arthrodesis using a posterior blade plate. $(\mathbf{O})$ postoperative mortise and $(\mathbf{P})$ lateral view radiographs show the tibiotalocalcaneal arthrodesis. 

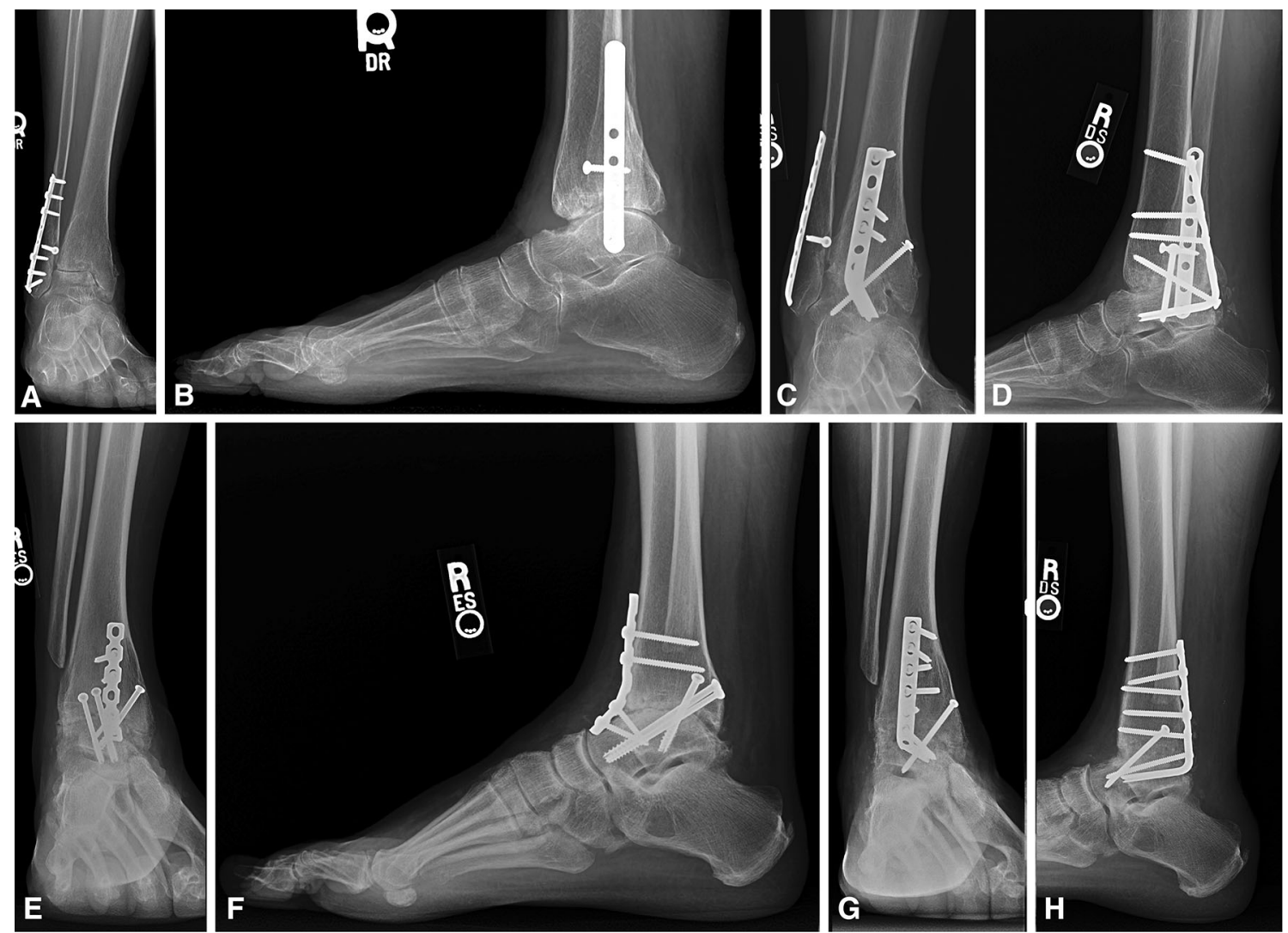

Fig. 2A-H (A) Preoperative mortise and (B) lateral view radiographs of the ankle of an 83-year-old female patient with posttraumatic tibiotalar osteoarthritis are shown. (C) The mortise and (D) lateral view radiographs of the patient's ankle after undergoing primary tibiotalar arthrodesis are shown. (E) AP and
(F) lateral view radiographs show a tibiotalar nonunion in a 55-yearold male patient. He underwent a revision tibiotalar arthrodesis with a posterior blade plate as seen on his $(\mathbf{G})$ postoperative AP and $(\mathbf{H})$ lateral view radiographs.

taken down and the lateral ankle gutter was débrided from the posterior approach. Two 4-mm cortical screws then were placed from the lateral incision to fuse the syndesmosis with one screw gaining purchase in the tibia and the other in the talus.

After all the hardware was inserted, the Achilles tendon was repaired in a lengthened state with a nonabsorbable suture. The paratenon was closed with a running 2-0 absorbable suture and finally, the skin with a 3-0 nylon suture.

Then a well-padded, below-the-knee splint was placed for 2 weeks and the patients were kept nonweightbearing. At 2 weeks a cast was applied and the patients were kept nonweightbearing for an additional 4 to 8 weeks. Between 6 to 10 weeks, patients were transitioned to wearing a below-knee walker boot with the timing of transition determined by radiographic evidence of bone healing. If radiographs showed evidence of early consolidation, then progressive partial weightbearing was initiated. The boot was used for 12 to 16 weeks, with the goal of transitioning from the boot at that time. 
Fig. 3A-E Anatomic landmarks for a $10-\mathrm{cm}$ straight midline posterior incision were marked on the (A) lateral, (B) dorsal, and (C) medial aspects of the ankle. A (D) transtendinous approach was performed using a Z-type lengthening of the Achilles tendon. (E) The posterior capsules of the ankle and subtalar joins were incised.
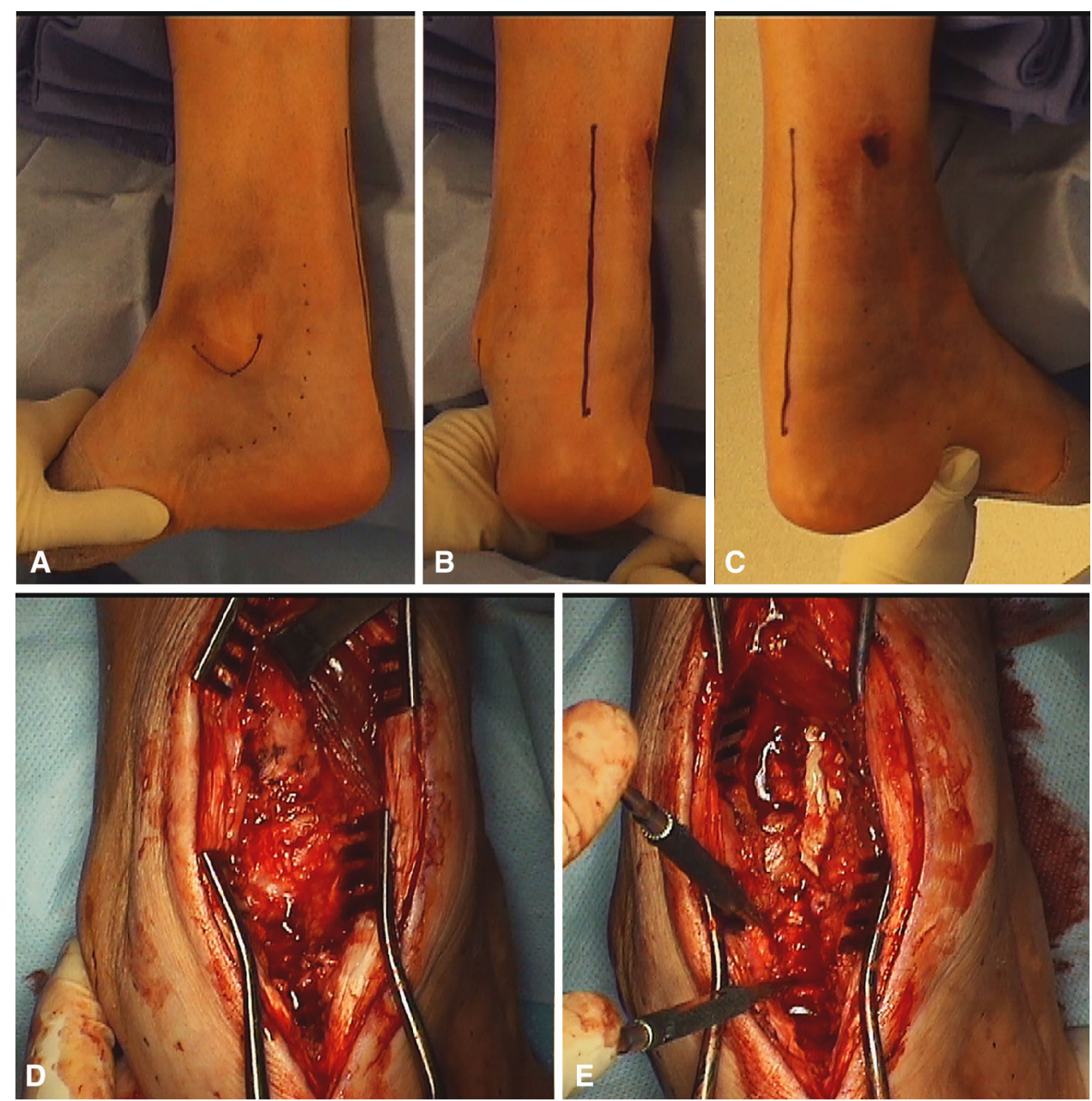

Affected ankles were evaluated based on weightbearing radiographs in two planes (AP and lateral ankle views) at 6 weeks (nonweightbearing radiographs), 3 months, 6 months, 1 year, and then annually thereafter. Fusion was defined as satisfying clinical criteria (no pain, no warmth, improvement in swelling, and stability to stress) and radiographic criteria (visible trabecular bridging across the arthrodesis site and no lucency around the hardware). All radiographs including weightbearing AP and lateral views of the ankle were evaluated by two orthopaedic surgeons (TMG, AB), each of whom was blinded to all other patient data. Additionally, original radiology reports were reviewed. Appropriate osseous union was defined as trabecular bridging across the arthrodesis within 6 postoperative months. Delayed osseous union was defined as arthrodesis between 6 and 12 months. Nonunion was defined as missing osseous union at the latest followup, at least 12 months after surgery. Findings were considered valid when consensus was achieved among all observers. When indicated, CT was performed to assess for union and was evaluated by independent radiologists at the University of Utah.

Nonunion, delayed union, deep infection resulting in a secondary procedure, severe persisting pain syndrome, and deep vein thrombosis were considered major complications. Superficial infection, delayed wound healing, stress fracture not resulting in a secondary procedure, and peripheral neuritis were considered minor complications.

Independent variables included age, gender, BMI, diabetes mellitus, history of smoking, peripheral neuropathy, type of surgery, and use of BMP (rhBMP-2, Medtronic, Minneapolis, MN, USA). Dependent variables were fusion date and postoperative complications. All data were extracted by independent chart and radiograph review by qualified authors (TMG, ML, AB) who had not performed the operations. Followup periods were based on standard of care visits at 3 weeks, 6 weeks, 12 weeks, 6 months, 1 year, and annually thereafter. Any additional visits recommended by the provider or requested by the patient also were reviewed. 


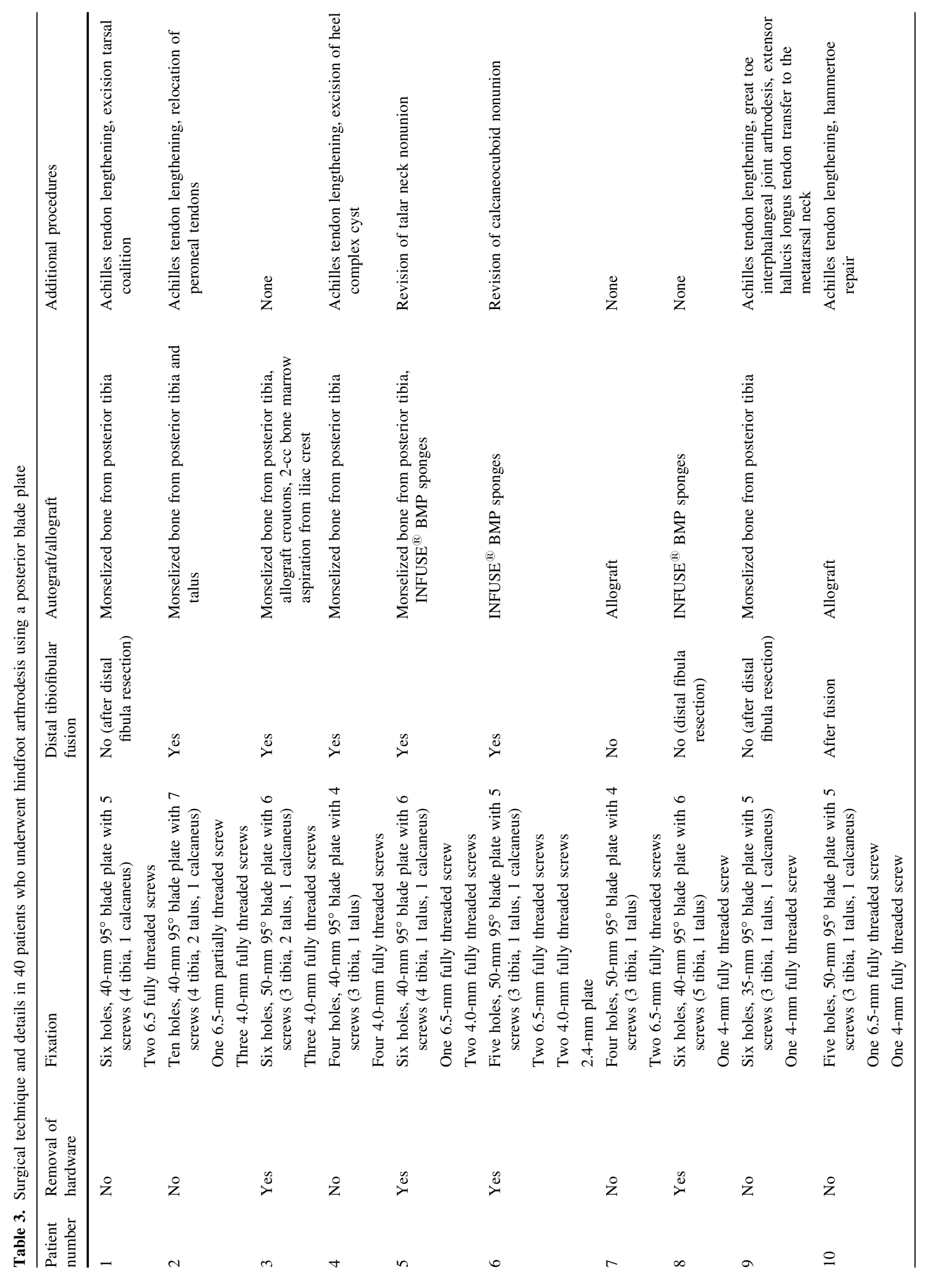




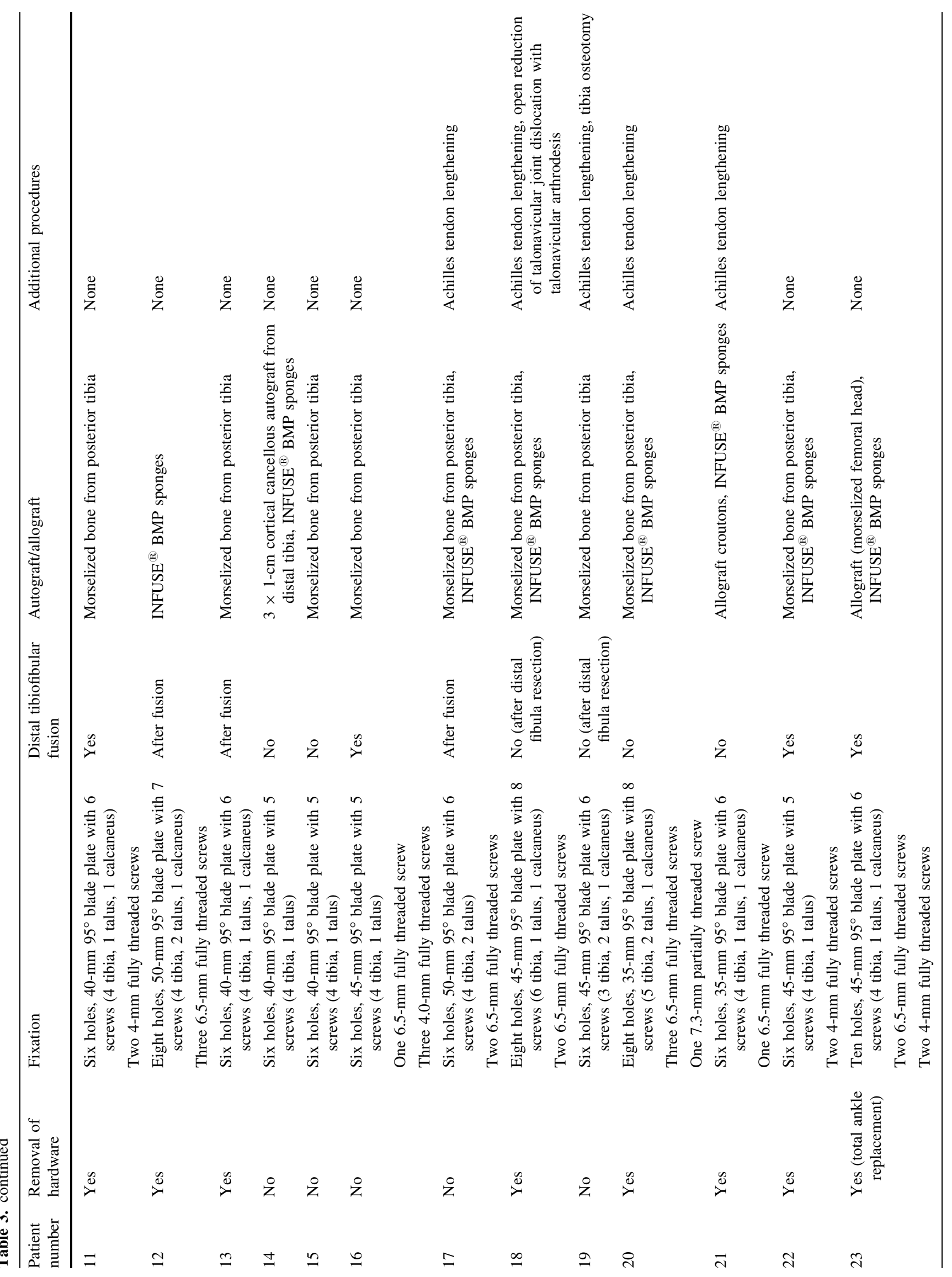




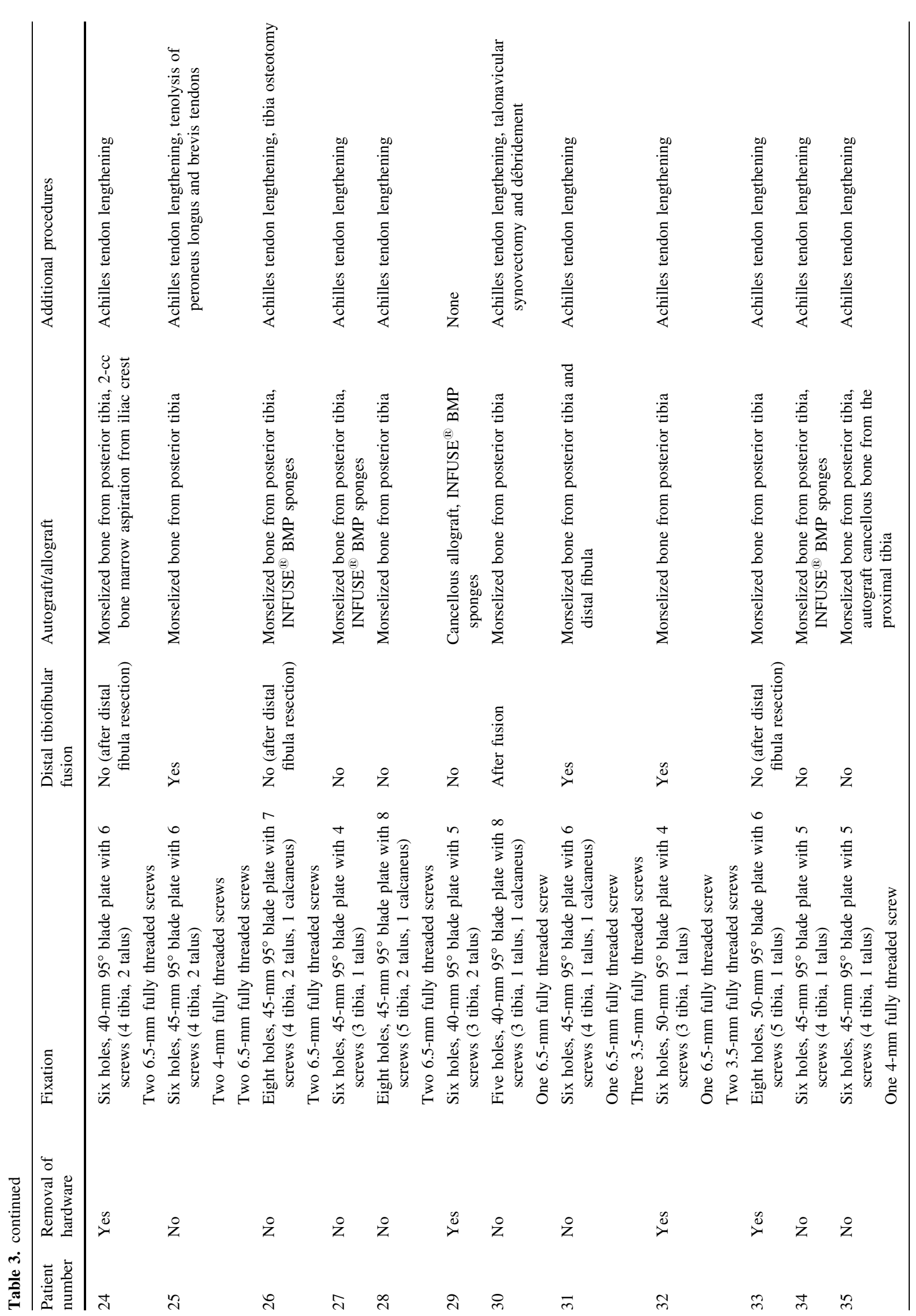




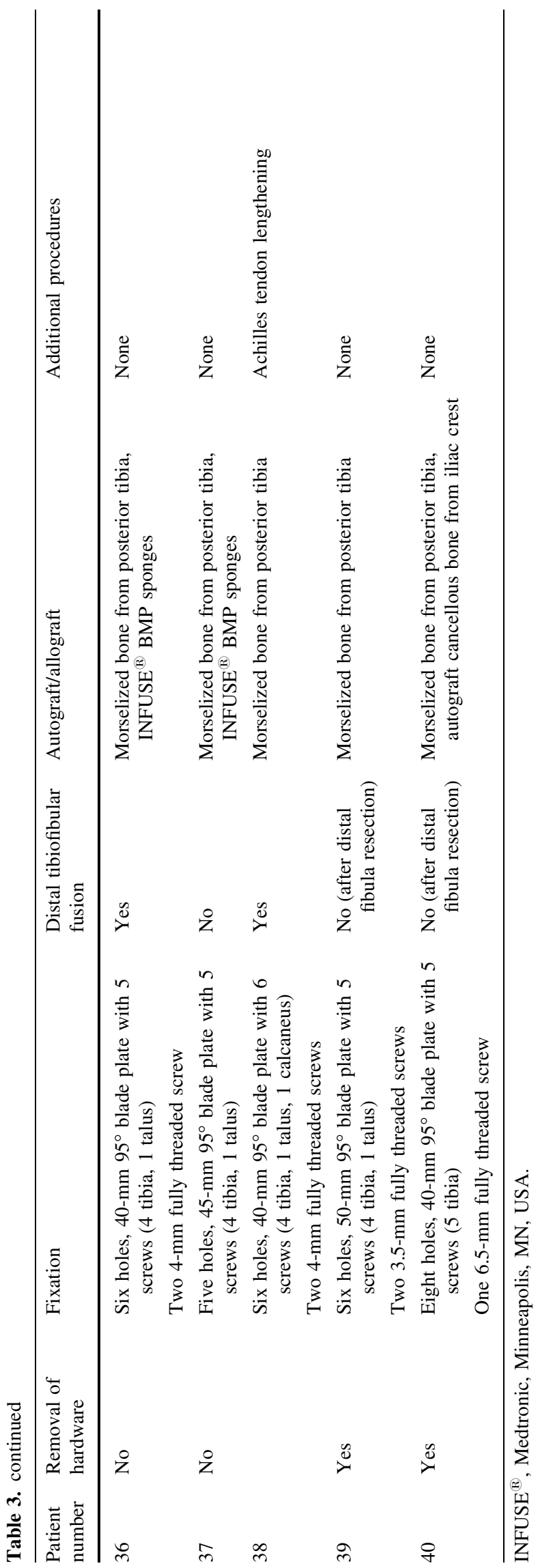

Statistical Analysis

A Kolmogorov-Smirnov normality test was performed to determine if data were normally distributed. A univariate regression for comparison of two groups-those with complications and those without-was performed with the following factors: age, gender, BMI, diabetes mellitus, smoking, peripheral neuropathy, type of surgery, and use of BMP. A p value of 0.05 or less was considered statistically significant. Data were analyzed using IBM $^{\circledR}$ SPSS $^{\circledR}$ Statistics Version 22 (IBM Corporation, Armonk, NY, USA) and SigmaPlot Version 12.5 (Systat Software Inc, San Jose, CA, USA).

\section{Results}

Fusion was achieved by $83 \%$ of the patients in this series (33 of 40) (Table 4). Four of the 33 patients (12\%) with ultimate union had a delayed union. All patients who experienced a nonunion (seven of $40 ; 18 \%$ ) had undergone a tibiotalocalcaneal arthrodesis: primary tibiotalocalcaneal arthrodesis in two cases, primary-staged tibiotalocalcaneal arthrodesis in four cases, and revision tibiotalocalcaneal arthrodesis in one case.

The seven nonunions included three ankle nonunions (43\%), three subtalar nonunions $(43 \%)$, and a combined nonunion in one patient (14\%) (Table 5). In one patient, nonunion was associated with a deep infection resulting in two irrigations and débridements, lateral calcaneal artery rotational flap coverage, and hardware removal. The subtalar joint united in this patient and the patient functions with the ankle nonunion with preserved hindfoot alignment.

Another patient with ankle nonunion presented with failed hardware (one broken screw). Despite the nonunion, he was asymptomatic and refused revision surgery. In the third patient with an ankle nonunion, hardware removal and revision arthrodesis using an intramedullary nail was performed 9 months after the index surgery. At the latest followup, 13 months after the revision arthrodesis, a solid fusion was observed.

In one patient with subtalar nonunion, revision surgery was performed 11 months after the index surgery, which resulted in complete osseous healing. Another patient with subtalar nonunion had few symptoms and a well-aligned hindfoot; therefore, no revision surgery was indicated. In the third patient, revision of the painful subtalar nonunion was performed 10 months after the index surgery. However, union still was not observed, and the patient presented with worsening symptoms. Five months later, a below knee amputation was performed.

In the patient with combined ankle and subtalar nonunions, hardware failure with plate breakage resulted in substantial 


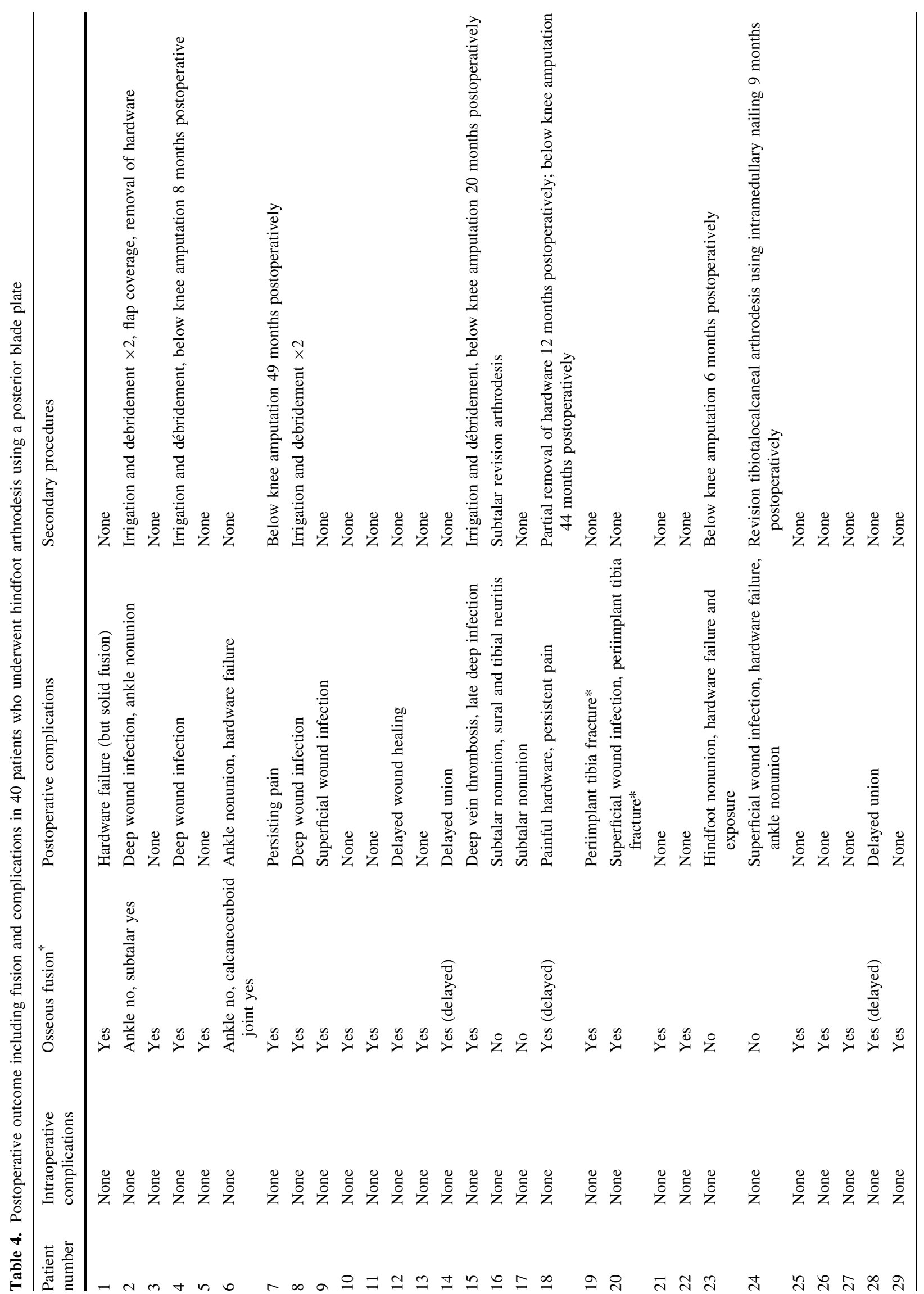




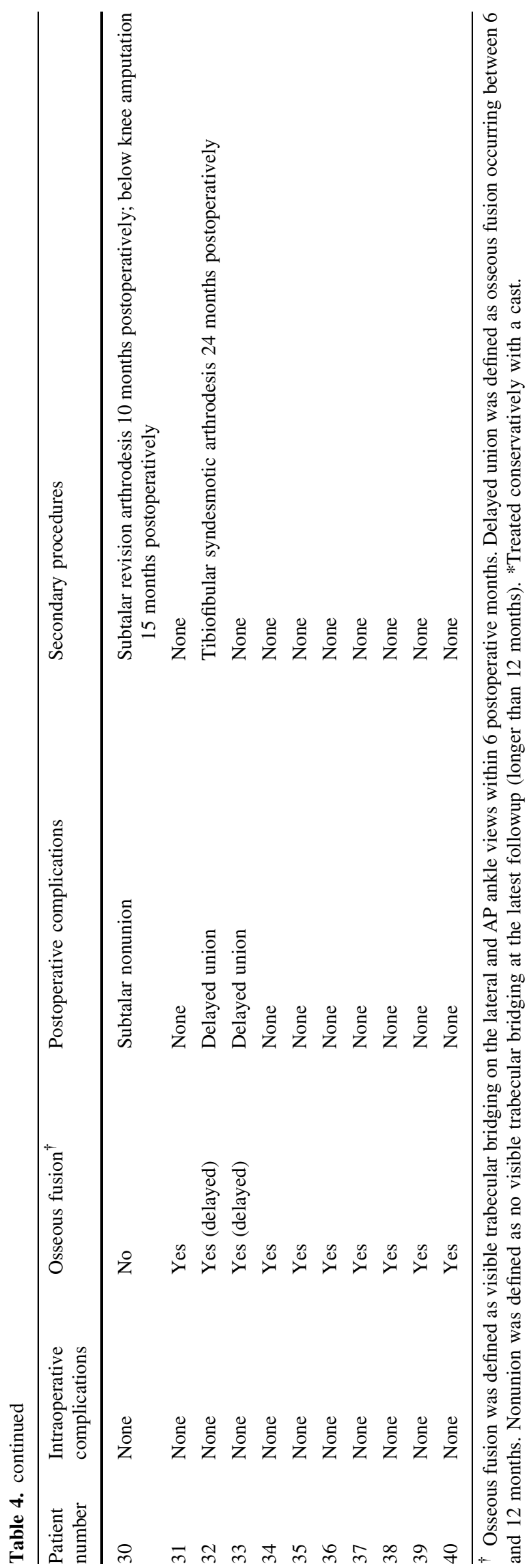

varus collapse of the hindfoot. A below knee amputation was performed 6 months after the initial fusion attempt.

With the numbers available, we identified no demographic or health-related patient factors associated with nonunion (Table 5).

Complications were common in this series. We observed 18 major and eight minor complications as earlier defined. When accounting for the occurrence of more than one complication in some patients, a total of $40 \%$ of patients (16 of 40) experienced one or more major complication and a total of $18 \%$ (seven of 40 ) experienced one or more minor complication.

Including the delayed unions and nonunions as described previously, 21 of 40 patients (53\%) had complications (Table 4). Eighteen complications were considered major (seven nonunions, four deep infections, four delayed unions, two severe persisting pain syndromes, one deep vein thrombosis) and eight complications were considered minor (three delayed wound healings, two tibial stress fractures, one superficial infection, one neuritis, one hardware failure but solid fusion). Patients with or without complications were comparable in terms of demographic data and surgical details (Table 6).

Four of 40 patients (10\%) had a deep infection treated by secondary surgery and intravenous antibiotics. One of the deep infections was associated with nonunion of the ankle as described previously. In another patient, irrigation and débridement was performed to treat the deep infection; however, infection and pain could not be resolved and a below knee amputation was performed. The third deep infection occurred 18 months after the index procedure in a 58-year-old patient who was a smoker and also had liver cirrhosis. This patient also had a deep vein thrombosis develop. Limb salvage was attempted with irrigation and débridement; however owing to persistent infection and pain, a below knee amputation was performed. The fourth deep infection occurred in a 55-year-old patient with diabetes and neuropathy who smoked. This patient underwent two irrigation and débridement procedures and the infection was resolved.

One patient had persistent pain without reflex sympathetic dystrophy despite successful fusion as confirmed by CT. After all conservative treatment options failed, a below knee amputation was performed 49 months after the index surgery. Another patient also reported severe, persistent pain without reflex sympathetic dystrophy. Twelve months after the index surgery, partial hardware removal was performed. However, this did not result in pain relief; therefore, 44 months after the initial surgery, a below knee amputation was performed.

The most serious superficial wound issue was a dehiscence that occurred 6 weeks after surgery associated with a superficial infection. The patient was treated successfully for the infection with oral antibiotics and wet-to-dry dressing changes. 
Table 5. Demographic data and surgical details of 36 patients*

\begin{tabular}{|c|c|c|c|c|}
\hline Parameter & Patients with solid union & Patients with nonunion & $\mathrm{p}$ value & Power analysis $\$$ \\
\hline Number of patients (ankles) & $29(29)$ & $7(7)$ & - & \\
\hline Mean age (years; range) & $55(24-76)$ & $57(52-66)$ & $0.674^{\dagger}$ & 0.108 \\
\hline Gender: male:female & $20: 9$ & $5: 2$ & $0.641^{*}$ & 0.049 \\
\hline Mean BMI $\left(\mathrm{kg} / \mathrm{m}^{2} ;\right.$ range $)$ & $29(18-42)$ & $29(26-33)$ & $0.969^{\dagger}$ & 0.069 \\
\hline Diabetes mellitus, yes:no & $9: 20$ & $1: 6$ & $0.645^{*}$ & 0.134 \\
\hline Smoking, yes:no & $8: 21$ & $3: 4$ & $0.650^{\ddagger}$ & 0.115 \\
\hline Peripheral neuropathy, yes:no & $11: 18$ & $1: 6$ & $0.384^{*}$ & 0.206 \\
\hline Arthrodesis ankle:tibiotalocalcaneal & $8: 21$ & $0: 7$ & $0.309^{*}$ & 0.333 \\
\hline Arthrodesis, primary:revision & $16: 13$ & $4: 3$ & $0.925^{*}$ & 0.048 \\
\hline Use of recombinant human BMP-2, yes:no & $13: 16$ & $2: 5$ & $0.674^{*}$ & 0.114 \\
\hline
\end{tabular}

* Four patients with delayed osseous union were excluded from this analysis; ${ }^{\$}$ post priory power analysis with an $\alpha$ of 0.05 ; ${ }^{\dagger}$ unpaired t-test; "Fisher's exact test.

Table 6. Demographic data and surgical details of 40 patients

\begin{tabular}{|c|c|c|c|c|}
\hline Parameter & $\begin{array}{l}\text { Patients without } \\
\text { complications }\end{array}$ & $\begin{array}{l}\text { Patients with minor } \\
\text { complications }\end{array}$ & $\begin{array}{l}\text { Patients with major } \\
\text { complications }\end{array}$ & $\mathrm{p}$ value* \\
\hline Number of patients (ankles) & $19(19)$ & $6(6)$ & $15(15)$ & $-1-$ \\
\hline Mean age (years; range) & $55.6(23.7-83.2)$ & $56.6(28.5-75.5)$ & $57.3(33.0-74.9)$ & $\begin{array}{c}0.715^{\dagger} / \\
0.887^{\dagger}\end{array}$ \\
\hline Gender, male:female & $11: 8$ & $3: 3$ & $13: 2$ & $\begin{array}{c}0.128 \% \\
0.734\end{array}$ \\
\hline Mean BMI $\left(\mathrm{kg} / \mathrm{m}^{2}\right.$; range $)$ & $29.3(18.1-41.9)$ & $30.4(24.6-38.2)$ & $28.6(22.5-38.0)$ & $\begin{array}{c}0.739^{\dagger} / \\
0.728^{\dagger}\end{array}$ \\
\hline Diabetes mellitus, yes:no & $6: 13$ & $2: 4$ & $3: 12$ & $\begin{array}{c}0.697 \% \\
0.936\end{array}$ \\
\hline Smoking, yes:no & $4: 15$ & $2: 4$ & $5: 10$ & $\begin{array}{c}0.462 \% \\
0.606\end{array}$ \\
\hline Peripheral neuropathy, yes:no & $5: 14$ & $4: 2$ & $3: 12$ & $\begin{array}{c}0.666 \% \\
0.142\end{array}$ \\
\hline $\begin{array}{l}\text { Arthrodesis } \\
\text { ankle:tibiotalocalcaneal }\end{array}$ & $8: 11$ & $3: 12$ & $0: 6$ & $\begin{array}{c}0.271 \% \\
0.129\end{array}$ \\
\hline Arthrodesis, primary:revision & $12: 7$ & $2: 4$ & $10: 5$ & $\begin{array}{c}0.832 \% \\
0.350\end{array}$ \\
\hline
\end{tabular}

$\bar{*}$ Without complications versus with minor complications/without complications versus major complications; ${ }^{\dagger}$ unpaired t-test; ${ }^{*}$ Fisher's exact test.

Two tibial stress fractures occurred at the top of the blade plate, one at 4 months and the other at 4.5 months after the index procedure. Both patients were treated with a below knee cast for 4 weeks and were nonweightbearing. Both stress fractures healed without additional complications.

Another minor complication included one case of tibial and sural neuritis, which was completely resolved at the 6month postoperative followup.

With the numbers available, we identified no demographic or health-related patient factors associated with the development of complications (Table 6).

\section{Discussion}

The use of a blade plate is a well-accepted fixation treatment for hindfoot arthrodesis. However, few articles have addressed clinical outcomes in patients who underwent hindfoot arthrodesis using a blade plate from a posterior approach (Table 1), and these are limited by small patient populations and shorter followup (Table 1). In the current study, we asked: (1) What proportion of patients treated with this technique achieved osseous union? (2) What complications were observed? (3) Were any patient- 
demographic or health-related factors associated with the likelihood that a patient would have a complication develop? We found that the proportion of patients treated with a posterior blade-plate hindfoot fusion who had delayed union and nonunion was greater than that reported for patients in other series who underwent primary hindfoot arthrodesis with other approaches, and the proportion of patients with complications was high. With the numbers available, we did not identify any demographic or surgical factors associated with complications, delayed union, or nonunion.

Our study has numerous limitations. First, it is retrospective. The outcomes reported in this study rely on accuracy of the clinic notes. Surgeon bias may have influenced the clinical records. We cannot know to what extent this form of bias might have affected our assessment of outcomes. However, all radiographic assessments were performed independently anew for this study. Second, it does not include patient-reported clinical outcomes. We can only surmise that for some patients who had revision or secondary procedures, including amputations, the outcomes for them from the posterior ankle/subtalar bladeplate surgery were inadequate. Third, in our study, weightbearing conventional radiographs were used to evaluate the fusion status. CT scans have been shown to have high reliability in determining the degree of successful fusion of the hindfoot [6]. However, in our study, only patients with a suspected nonunion or delayed union underwent $\mathrm{CT}$, as it would be impractical to obtain $\mathrm{CT}$ in all patients. Fourth, the number of patients treated by posterior blade-plate arthrodesis was relatively small. Therefore, with the available number, we were not able to identify any demographic or surgical factors associated with complications, delayed union, or nonunion.

Available studies including patients with posterior blade-plate arthrodesis included less-complicated patient populations with no surgical history in the affected ankle and who were without significant medical comorbidities. One of the first reports of the use of posterior blade plates was by Gruen and Mears [14], who described their technique for the posterior approach and posterior blade plating for arthrodesis of the ankle and subtalar joints in five patients. More recently, posterior blade plating has been used successfully for definitive treatment of nonreconstructable pilon fractures [5, 19, 27, 28]. Bozic et al. [5] treated 14 patients with ankle incongruence after nonreconstructable tibial pilon fractures with primary ankle arthrodesis using a posterior blade plate. In a 2010 report, Cinar et al. [9] performed tibiocalcaneal arthrodesis using a posterior blade plate in four patients with diabetes and with Charcot arthropathy.

Delayed union and nonunion were more common in our study than in others that have used posterior blade-plate hindfoot arthrodesis (Table 1). In the report by Gruen and Mears [14], all patients experienced complete osseous union and no complications were described. Similarly, Hanson and Cracchiolo [16] reported $100 \%$ union at an average followup of 37 months; however, two patients experienced delayed union, and complications were reported in five (50\%). Cinar et al. [9] reported the development of solid fusion in three of four patients at a mean followup of 24 months. However, two of the four patients experienced wound infections, and one patient underwent hardware removal [9]. Bozic et al. [5] reported that all 14 patients receiving treatment for traumatic pilon fractures using a posterior blade plate achieved fusion at an average of 15 weeks, with osseous union being defined as full weightbearing with minimal pain and radiographic evidence of arthrodesis on conventional radiographs. There was one deep infection which resulted in implant removal and intravenous antibiotics. One patient had a broken plate but achieved successful fusion without reoperation [5].

Complications, likewise, were more common in our series than in others using the posterior approach with a blade plate for hindfoot arthrodesis $[1,5,9,14-16,19,27,28]$. A possible explanation for this finding may be that most of our patients had at least one previous surgery compromising soft tissues around the ankle. With the numbers available, we did not identify any factors associated with postoperative complications or nonunion. Although sources are limited regarding the use of rhBMP-2 in patients with foot and ankle disorders, some authors suggest it is effective in aiding union after arthrodesis [4, 13, 23]. Seventeen of our patients received rhBMP-2 during the index procedure either exclusively or in combination with local bone grafting. Bibbo et al. [4] and Rearick et al. [23] did not find the presence or absence of grafting to have an effect on union rates when used with rhBMP-2. Analysis of our patients showed no difference in union rates with and without the use of rhBMP-2 with the numbers available. More investigation is necessary to determine if rhBMP-2 has a role in hindfoot and ankle fusion surgery. Previous arthrodesis of the adjacent joint is a risk factor for nonunion of the tibiotalar joint (with a previously fused subtalar joint) [7] or of the subtalar joint (with a previously fused tibiotalar joint) $[12,26]$. Easley et al. [11], whose study included only patients who underwent revision arthrodesis, reported a union rate that was comparable to the rate in our patients. At the time of the most recent follow up-an average of 50 months-the union rate was $89 \%$. We did not observe a positive effect of rhBMP-2 most likely owing to the low number of patients in our study. In our patient cohort, six of seven patients $(86 \%)$ with primary isolated ankle arthrodesis had a complete osseous union. Another possible explanation for the high number of patients with nonunion or delayed union is 
the possibly high invasiveness of this fixation method. It is not clear whether a blade plate may disrupt intraosseous blood supply of the talus which would increase the risk of compromised osseous healing.

Our patients undergoing hindfoot arthrodesis through a posterior blade plate were a diverse and challenging group. Most of the patients had one or more previous ankle or hindfoot surgeries. Nonunion was more common than reported in other series $[1,5,9,14-16,19,27,28]$ and complications also were more common $[1,5,9,14-16,19,27,28]$. However, specifically in patients with compromised anterior, medial, and lateral soft tissue envelopes, a posterior approach with blade-plate fixation can be considered a viable surgical option. Further clinical studies are necessary to address alternative approaches, such as hybrid fixation types external and internal, to achieve better results and higher union rate in patients with complex hindfoot problems.

Acknowledgments We thank S. Craig Morris MD (Department of Orthopaedics, University of Utah, Salt Lake City, UT, USA) for contributions to data collection for this study.

\section{References}

1. Acosta R, Ushiba J, Cracchiolo A 3rd. The results of a primary and staged pantalar arthrodesis and tibiotalocalcaneal arthrodesis in adult patients. Foot Ankle Int. 2000;21:182-194.

2. Anderson JG, Bohay DR, Maskill JD, Gadkari KP, Hearty TM, Braaksma W, Padley MA, Weaver KT. Complications after popliteal block for foot and ankle surgery. Foot Ankle Int. 2015;36:1138-1143.

3. Anderson JG, Coetzee JC, Hansen ST. Revision ankle fusion using internal compression arthrodesis with screw fixation. Foot Ankle Int. 1997;18:300-309.

4. Bibbo C, Patel DV, Haskell MD. Recombinant bone morphogenetic protein-2 (rhBMP-2) in high-risk ankle and hindfoot fusions. Foot Ankle Int. 2009;30:597-603.

5. Bozic V, Thordarson DB, Hertz J. Ankle fusion for definitive management of non-reconstructable pilon fractures. Foot Ankle Int. 2008;29:914-918.

6. Cerrato RA, Aiyer AA, Campbell J, Jeng CL, Myerson MS. Reproducibility of computed tomography to evaluate ankle and hindfoot fusions. Foot Ankle Int. 2014;35:1176-1180.

7. Chalayon O, Wang B, Blankenhorn B, Jackson JB 3rd, Beals T, Nickisch F, Saltzman CL. Factors affecting the outcomes of uncomplicated primary open ankle arthrodesis. Foot Ankle Int. 2015;36:1170-1179.

8. Cheng YM, Chen SK, Chen JC, Wu WL, Huang PJ, Chiang HC, Lin CY. Revision of ankle arthrodesis. Foot Ankle Int. 2003;24:321-325.
9. Cinar M, Derincek A, Akpinar S. Tibiocalcaneal arthrodesis with posterior blade plate in diabetic neuroarthropthy. Foot Ankle Int. 2010;31:511-516.

10. Deleu PA, Devos Bevernage B, Maldague P, Gombault V, Leemrijse T. Arthrodesis after failed total ankle replacement. Foot Ankle Int. 2014;35:549-557.

11. Easley ME, Montijo HE, Wilson JB, Fitch RD, Nunley JA 2nd. Revision tibiotalar arthrodesis. $J$ Bone Joint Surg Am. 2008;90:1212-1223.

12. Easley ME, Trnka HJ, Schon LC, Myerson MS. Isolated subtalar arthrodesis. J Bone Joint Surg Am.2000;82:613-624.

13. Fourman MS, Borst EW, Bogner E, Rozbruch SR, Fragomen AT. Recombinant human BMP-2 increases the incidence and rate of healing in complex ankle arthrodesis. Clin Orthop Relat Res. 2014;472:732-739.

14. Gruen GS, Mears DC. Arthrodesis of the ankle and subtalar joints. Clin Orthop Relat Res. 1991;268:15-20.

15. Hammit MD, Hobgood ER, Tarquinio TA. Midline posterior approach to the ankle and hindfoot. Foot Ankle Int. 2006;27:711715 .

16. Hanson TW, Cracchiolo A 3rd. The use of a 95 degree blade plate and a posterior approach to achieve tibiotalocalcaneal arthrodesis. Foot Ankle Int. 2002;23:704-710.

17. Hopgood P, Kumar R, Wood PL. Ankle arthrodesis for failed total ankle replacement. J Bone Joint Surg Br. 2006;88:1032-1038.

18. Kotnis R, Pasapula C, Anwar F, Cooke PH, Sharp RJ. The management of failed ankle replacement. J Bone Joint Surg Br. 2006;88:1039-1047.

19. Morgan SJ, Thordarson DB, Shepherd LE. Salvage of tibial pilon fractures using fusion of the ankle with a 90 degrees cannulated blade-plate: a preliminary report. Foot Ankle Int. 1999;20:375-378.

20. Nickisch F, Avilucea FR, Beals T, Saltzman C. Open posterior approach for tibiotalar arthrodesis. Foot Ankle Clin. 2011;16:103114.

21. Nihal A, Gellman RE, Embil JM, Trepman E. Ankle arthrodesis. Foot Ankle Surg. 2008;14:1-10.

22. Rammelt S, Pyrc J, Agren PH, Hartsock LA, Cronier P, Friscia DA, Hansen ST, Schaser K, Ljungqvist J, Sands AK. Tibiotalocalcaneal fusion using the hindfoot arthrodesis nail: a multicenter study. Foot Ankle Int. 2013;34:1245-1255.

23. Rearick T, Charlton TP, Thordarson D. Effectiveness and complications associated with recombinant human bone morphogenetic protein-2 augmentation of foot and ankle fusions and fracture nonunions. Foot Ankle Int. 2014;35:783-788.

24. Shah KS, Younger AS. Primary tibiotalocalcaneal arthrodesis. Foot Ankle Clin. 2011;16:115-136.

25. Thomas RL, Sathe V, Habib SI. The use of intramedullary nails in tibiotalocalcaneal arthrodesis. J Am Acad Orthop Surg. 2012;20:1-7.

26. Zanolli DH, Nunley JA 2nd, Easley ME. Subtalar fusion rate in patients with previous ipsilateral ankle arthrodesis. Foot Ankle Int. 2015;36:1025-1028.

27. Zelle BA, Gruen GS, Espiritu M, Pape HC. Posterior blade plate fusion: a salvage procedure in severe posttraumatic osteoarthritis of the tibiotalar joint. Oper Tech Orthop. 2006;16:68-75.

28. Zelle BA, Gruen GS, McMillen RL, Dahl JD. Primary arthrodesis of the tibiotalar joint in severely comminuted high-energy pilon fractures. J Bone Joint Surg Am. 2014;96:e91. 